\title{
Silence and Visual Representations of Anti-Violence Campaigns in Cosmopolitan Brisbane
}

\author{
Victor Igreja
}

\begin{abstract}
Aвstract: In spite of the growing public focus on domestic violence (DV) in mainstream Australian society, ethnographers have remained aloof from analysing this problem. In an ethnographic study in the Brisbane region, I analysed people's perceptions of anti-violence images that were part of a public campaign and assessed the appropriateness of the images' locations. Occasionally, my interlocutors unexpectedly included accounts of DV. My analysis reveals the tensions between public display and the concealment underlying the campaign. The interlocutors revealed experiences of competing responsibilities related to DV. The use of subtle images of anti-violence in locations filled with competing images, coupled with a failure to consider historical continuities and changes in local imaginaries of violence, exposed the difficulties associated with conveying persuasive messages of DV prevention.
\end{abstract}

KeYwords: domestic violence, ethnography, persuasive messages, prevention, silence, visual representations

Modern anthropology has produced an array of ethnographic studies of diverse types of violence around the globe (Green 1999; Riches 1986; Whitehead and Finnström 2013), yet it has not produced analyses of domestic violence (DV) among mainstream communities in developed high-income countries. The pervasiveness of DV in these countries has been the focus of psychological, sociological and public health studies. In these studies, there is robust evidence, consistent with figures around the world, pinpointing males as perpetrators and females as victims, and the degrading consequences of DV (Krug et al. 2002). However, the reasons for the occurrence and processes of DV in specific locations, the dynamics of silence in social relations (cf. Green 1999: 5) and the best strategies to break silence and prevent violence remain matters of serious debate in Australia (Donovan et al. 1999; Gadd et al. 2014; Kitzinger 1994: 252).

Critical analysis, undertaken mainly by historians (Evans 1992; Reynolds 1972), of the few reports published in the 1970s on violence against women in Australia reveals that these reports did not challenge 'the dominant regimes of representation' (Hall 1990: 225) which were informed by the bifurcated structure of society. Violence was regarded as a widespread disordering phenomenon among Aboriginal populations. Thus, these communities were the subject of public surveillance, commissions of inquiry, and state disciplinary actions (Hernández 1941; Kahn 1980; Meggitt 1964). On the other hand, mainstream Australians were romanticised as uniquely peaceful (Reynolds 1972: 471). Violence perpetrated by mainstream Australians was treated as an embarrassing topic, and considered as an ephemeral feature of lower social classes; in public and in academic circles, the topic was avoided (Dixson 1976; Kahn 1980). In a slightly different analysis of gender and multiple subject positions in Australia, Katherine Gibson-Graham (1995) suggested that working class men were dominated by the employers within capitalist labour relations while the same men were in a dominant position vis-à-vis their wives and daughters in the domestic sphere. In the context of DV, the social relations of men and women in the mainstream, regard-

Anthropology in Action, 25, no. 1 (Spring 2018): 15-28 (C) Berghahn Books and the Association for Anthropology in Action ISSN 0967-201X (Print) ISSN 1752-2285 (Online) doi:10.3167/aia.2018.250103 
less of their social class, were in a dominant position vis-à-vis those of minority groups. Silence shaped the responses to DV among mainstream families, neighbours and state institutions. Only extreme cases of DV were occasionally brought to the attention of the authorities, but once dealt with these cases where archived (Saunders 1984). Such types of institutional and social silence have been highlighted by Michael Herzfeld (2005: 3) through his idea of 'cultural intimacy', which he argues is formed between ruling elites and ordinary citizens. Accordingly, cultural intimacy is 'the recognition of those aspects of an officially shared identity that are considered a source of external embarrassment' (3). From this perspective, silence about cases of DV in mainstream Australian communities constituted a form of collective action, albeit an embarrassing one, that contributed to safeguarding the status quo by providing 'insiders with their assurance of common sociality' (3).

In recent years and as part of the global circulation of feminist ideas on matters of gender equality and the elimination of all forms of violence against women (Connell 2003), there have been attempts to confront the status quo, reject silence and publicly denounce diverse types of violence in mainstream communities. There have been public revelations of historical sexual abuse perpetrated by priests against children (McDonald and Stuart 2017), personal and collective accounts of serious victimisation of women (Gebert 2016), and reports of homophobic violence (Tomsen 2003). Armed with public testimonies of mainstream victims of DV and statistical reports of the Australian Bureau of Statistics (ABS), the prime minister, Malcolm Turnbull, stated that DV 'has been overlooked, to some extent ignored, for far too long' (Ireland 2015). Former Prime Minister Julia Gillard publicly warned that 'women going into politics should expect rape threats' (Anderson 2016). Often, leaders who discuss DV in mainstream Australia do not explain why for a long time it was seldom discussed and why DV among Aboriginal groups was loudly denounced. Nor has it been explained why women in mainstream politics should expect threats of violence. Instead, the tendency has been to advance moral prescriptions focused on men and diffused politics of identity and nationalism. For instance, Turnbull described DV as 'unAustralian', and stated that 'real men don't hit women' (Ireland 2015). Taken together, these views express a sense of urgency to address DV in mainstream society, but they are also symptomatic of a problem that lacks a broader persuasive language that taps into the diverse practices of DV and the processes needed to address it in specific locations.
Alongside political speeches, academic research into DV in Australia has increased, but local ethnographic studies are notably absent. While there is a robust ethnographic literature which has exhaustively unpacked Aboriginal social life (to cite just a few, Altman and Hinkson 2010; Barker et al. 2016; Merlan 2006), ethnographers have remained mute regarding violent relationships in mainstream Australia. Nevertheless, this ethnographic absence is gradually changing through studies of contemporary mainstream Australian society (Hage 1998) as well as innovative studies focused on the intersections of mainstream and Aboriginal Australians in specific locations (Trigger and Martin 2016).

Hitherto, most explanations for the occurrence of DV in mainstream Australia have used psychiatric, legal or criminal frameworks, and they have often highlighted the role of alcohol abuse (Day and Fernandez 2015; Meyer 2011). Several prominent women have published autobiographies and articles, and given interviews revealing personal experiences of intimate partner violence (Batty 2015; Day and Fernandez 2015; Despoja 2015; Moss 2014; Taylor 2014; Trenoweth 2015). Despite this growing body of diverse literature and this increasing concern among political and social elites about DV, explanations for the widespread prevalence of DV are lacking, and there is no analysis of the ways in which the status quo still shapes the ways in which DV in mainstream circles is dealt with. If the DV statistics of the ABS are reasonably accurate, and the sense of outrage is justified, the problem of DV in mainstream Australia cannot be explained only in terms of mental illness, alcohol abuse, criminality, deviant behaviour and 'unAustralian' behaviour. I argue that ethnographic research can offer meaningful insights for the articulation of comprehensive anti-violence discourses in contemporary Australia, given the ability of the ethnography to provide close-up accounts in everyday life. Any such close-up account must take into consideration 'the concrete and specific experiences of people' (Green 1999: 11) and the evolving local histories, meanings, politics (Das et al. 1997) and intersubjective understandings of violence (Cerulo 1998: 31).

Taking advantage of an anti-violence campaign that unfolded in Brisbane and the surrounding cities, I analysed people's perceptions and interpretations of the anti-violence images on display, and I examined the appropriateness of these locations to reach out to social audiences in everyday life. I also examined the factors that encouraged and discouraged social audiences to engage with the images and help cards used in the campaign. 


\section{Talking Images and Anti-Violence Signs in Cosmopolitan Spaces}

Around the world, it is customary to use visual ads in campaigns (Wakefield et al. 2010) to direct people's attention to specific problems (Kilbourne 1999) including DV (Borzekowski and Poussaint 1999; Hill 2000). A growing body of research in criminology and socio-legal studies has also examined, for example, how, in the context of the courtroom, visual aids can convey the truth about domestic violence against women (Biber 2006; Moore and Singh 2017). In advertisement, it is believed that images can communicate the same message to large audiences repeatedly over time (Wakefield et al. 2010: 1262). However, in the contemporary world of visual sign wars, successfully gaining people's visual attention is a serious challenge (Goldman and Papson 1996), which is further complicated by the fact that images do not possess free-floating meanings (Belting 2011). Nevertheless, planners frame campaigns in attempts to seize people, retain their attention and ensure that they understand the intended message. For example, in Western and industrialised countries, photographs of people looking directly at the observer are used to tap directly into consumers' emotions (Malefyt and Morais 2012: 60; Messaris 1997: 5). The few existing studies of mass media campaigns that have focused on anti-violence have suggested that the timing (on radio and television), the format (billboards and posters) and the location of ads are key ingredients (Donovan et al. 1999; Kitzinger 1994). Increasingly, public toilets are used as sites for visual campaigns (Kaltenbaugh et al. 2011; Schapper 2012). Yet it is not clear whether such sites are appropriate for campaigns about contested topics such as DV, and it is not clear what types of images can best capture people's attention.

\section{Imaginaries of and Competing Responsibilities for Violence}

Anthropological and sociological studies have demonstrated that violence is not a natural phenomenon (Cerulo 1998; Riches 1986; Whitehead and Finnström 2013). Interpersonal and collective violence emerges in contexts of tense relations, and often there are contestations over its legitimacy (Riches 1986). This means that victims, perpetrators and bystanders often have disparate interpretations regarding the causes of and responsibilities for violence (Stewart and Strathern 2002). Violence is a multifaceted phenomenon related to order and disorder, and the meanings and interpretations of violence vary with time and place (Igreja 2015). Analysis of violence can be further complicated by a party having more than one subject position (Das et al. 1997; Green 1999). This means that an individual or group can be both victim and perpetrator, both witness and participant. An individual may be a whistle-blower about some types of violence but neglectful of other types. A person may denounce others' responsibility but be silent about their own.

In parallel to acts of violence, visual representations of violence and their interpretations can be shaped by people's imaginations, memories and associations, and by cultural repertoires and experiences of violence. This means that in the face of virtually identical images of violence social audiences can sometimes infer vastly different meanings (Cerulo 1998: 31; Igreja 2015). Thus, it is challenging to depict anti-violence in ways that firmly consider these above-mentioned complexities and that move beyond the customary views of men as perpetrators and women as victims (Gadd et al. 2014; Kitzinger 1994) and beyond hasty judgemental approaches (Donovan et al. 1999; Saunders and Taylor 2009).

\section{DVConnect and the 'Trust Your Instinct' Campaign}

In 2010, the Council of Australian Governments released the first 'National Plan to Reduce Violence against Women and their Children 2010-2022'. In Brisbane and the surrounding cities, DV Connect (DVConnect), a non-governmental organisation, developed the 'Trust Your Instinct' campaign in May 2015 in partnership with Queensland Rail and the Government of Queensland. The campaign aimed to increase community awareness of the fact that 'controlling and obsessive behaviours can seriously affect a person's emotional and psychological wellbeing, and may lead to serious injury or sometimes even homicide' (Help Card, DVConnect, s/d). ${ }^{1}$ The campaign also aimed to 'give people with concerns about someone they know information about warning signs and how to help' (Help Card, DVConnect, s/d). ${ }^{2}$

\section{Posters and Help Cards: \\ Controlling and Obsessive Behaviour}

The Trust Your Instinct campaign used advertising, social media, posters and help cards. ${ }^{3}$ My ethnographic focus was on two posters and one help card. Poster 1 (Figure 1) shows a coloured close-up of a woman's face. In the background, there is a hazy image of a person standing as if he was looking at 
the woman's back. Images in which the protagonist does not look at the viewer head-on are often used to convey spatial and temporal relations of events in a scene (Messaris 1997). The accompanying text states: 'He was controlling every move - who she saw, what she spent and what she wore. If I'd realised this was domestic violence, I would have acted out before it was too late'. It ends with: 'Don't let your concern become regret'. The help card for Poster 1 contains similar images. The text on the inside of the card describes DV and its impacts, explains how to identify its signs, and appeals to the reader to contact DVConnect if the person is experiencing, or knows someone who is experiencing, DV.

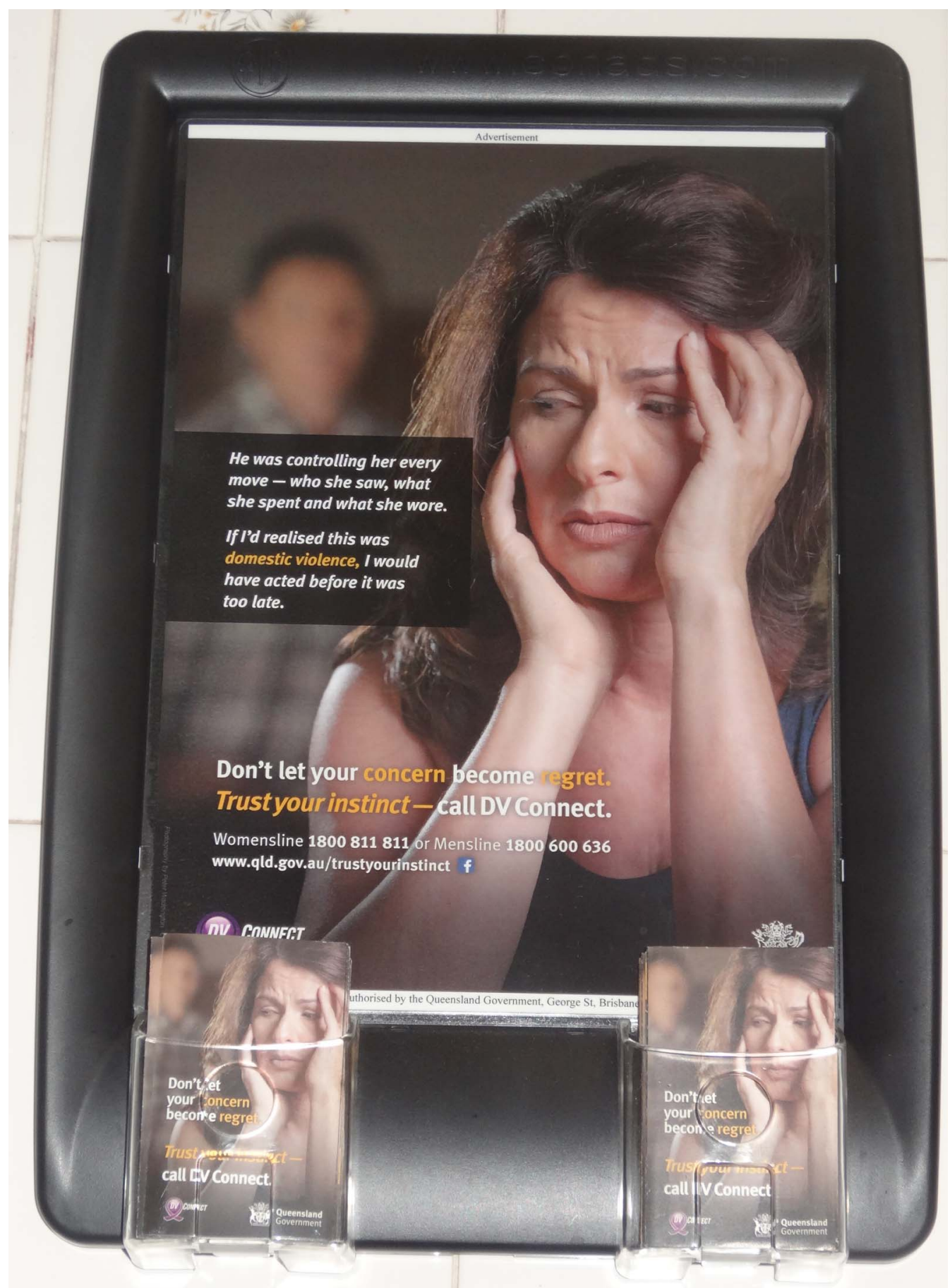

Figure 1: A poster of Trust Your Instinct campaign (photo by the author). 
Poster 2 (Figure 2) consists of a woman's face that is divided down the middle. The divided face is presented in a direct view, which implies an interaction between the viewer and viewed (Messaris 1997: 47). The woman's left eye appears to be injured. The text reads: 'Non-physical domestic violence such as controlling behaviour, stalking, threats and verbal abuse can quickly turn into physical abuse with sometimes fatal consequences'. This is followed by: 'If you feel concerned someone you know is being abused, don't wait - call DVConnect for confidential advice and support'.

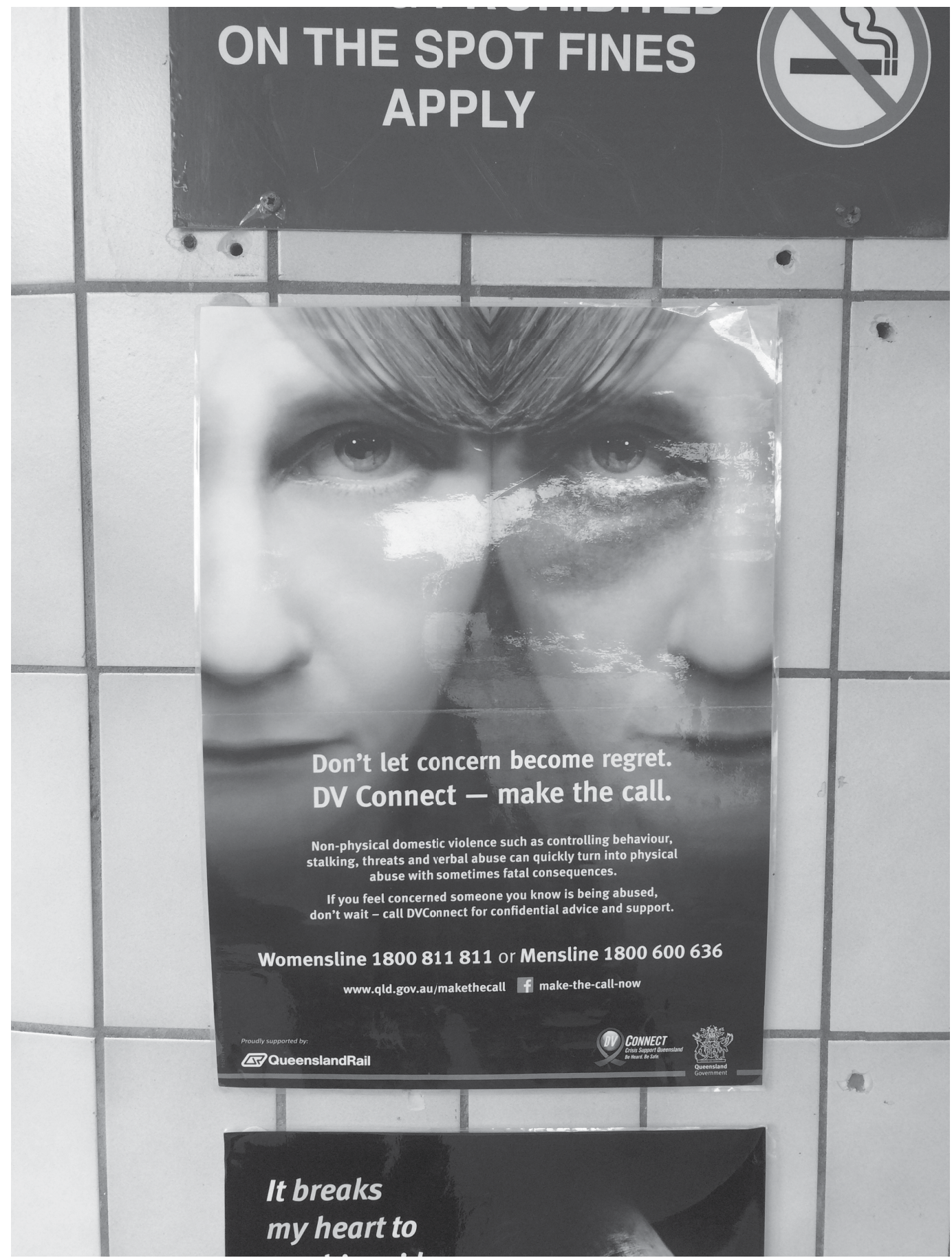

Figure 2: A poster of Trust Your Instinct campaign (photo by the author). 
Mapping the Broader Context:

A Brief Review of Gender Relations over Time

While the histories of women in mainstream Australia are not uniform, broad descriptions indicate that historically the subordinate positions of women can be traced to the gendered social inequalities that were pervasive in the country's colonial settlements in mid-nineteenth century (Moore 1998; Saunders 1984; Saunders and Taylor 2009; Spearritt 2009). According to Clive Moore (1998: 43), 'in Australia, dominant colonial Anglo-Celtic manhood and masculinity was constructed against the image of a multiple "other": women; recent immigrant males; nonCaucasian males; and limits of the expression of homosocial and homoerotic behaviour'. Women were expected to be caretakers of the home, while their husbands were the primary breadwinners (Encel et al. 1975: 42). This period was marked by a high incidence of marriage among adult women, and in Queensland the idea of obtaining security through marriage was prevalent (Saunders 1997: 126; Spearritt 2009: 47). Alongside beliefs that marriage offered protection to women, DV against women and their sexual exploitation were rampant. In parallel to settler-on-settler violence, there was 'deliberate violence against Aborigines as part of the colonial conquest of Australia: estimates suggest that around 2,000 settlers and perhaps 20,000 Aborigines died during frontier warfare' in the Brisbane region (Moore 1998: 44). DV was informed by male dominance and order, and it was seldom publicly denounced (Dixson 1976; Evans 1992; Kahn 1980; Spearritt 2009). Occasionally in Queensland, women were identified in public moral crusades as being to blame for problems for which both men and women, to a certain extent, shared responsibility (Saunders and Taylor 2009: 173). The reduction of complex social problems to a single public culprit continues to this day.

Following the Second World War, and as a result of the growing influence of feminism, some people's attitudes towards the position of women in Australia began to change (Caine and Pringle 1995). Gradually, women entered the workforce to meet the growing demands of emergent industries, and particularly towards the end of the 1960s there was a gradual increase in the number of women accessing higher education (Carrington and Pratt 2003). Since then, the rate of female participation in the labour market in Australia has been increasing (Uhlmann 2006: 35) and broader sociocultural and economic transformations have had an impact on gender relations (Baxter and Kane 1995). Yet, there remain various challenges to the attainment of comprehensive gender equality (Stilwell and Jordan 2007: 128), including addressing DV. In this historical context of globalisation and new modern aspirations, political elites and social campaign organisers have attempted to challenge the status quo that shielded silence over DV in mainstream Australia, and DV has officially become an unacceptable behaviour.

\section{Mapping Research Sites}

To select the sites for my research, I conducted an extensive ethnographic mapping of Brisbane and the surrounding cities to track visual signs of antiviolence campaigns. Adopting this visual grassroots approach, instead of asking the campaign organisers for help, allowed me to learn about how images shape local cosmopolitan sites, and to have many potential interlocutors become involved in multiple stages of my fieldwork. For six weeks, I asked people randomly if they had seen images of anti-violence campaigns somewhere around as I went to visit meaningful cosmopolitan sites. In the end, I found that the toilets located on the second and third floors of a major railway station in Brisbane were the focal point of the DVConnect Trust Your Instinct campaign. The campaign unfolded in more systematic ways in this location than in any of the other locations that I visited. I called these sites the Roma Street Station Toilets (henceforth, RSSTs), and the majority of my interviews unfolded in and around these sites.

Public toilets are not just physical spaces; they are also ambiguous locations encapsulating private and public dimensions (Schapper 2012). Time expectations are also a feature of such locations in that, in principle, three coordinated bodily actions are enough to give room for others. Thus, I initially felt uneasy about spending more time than is expected in the toilets. Nevertheless, soon I realised that basic acts of human interaction, like greetings, were enough to initiate simple conversations with other users. I used these brief occasions to introduce myself, explain that I was studying posters hung up in public locations and request their consent to participate in the research. They always responded positively and showed interest in issuing their views about the posters and help cards. Often, the respondents would want to know what I meant by posters, which provided further opportunities for expanding conversations. At other times, users knew and would rush to give their opinions about posters that they had seen in different locations. Throughout the study, I never once encountered unfriendly interlocutors or people who refused to talk with me. 
In Brisbane, as in most cities in Australia, public toilets (cf. Schapper 2012) and public transport are state-owned. Public toilets are gendered sites (Gershenson and Penner 2009; Schapper 2012), and I focused on male toilet users. It was only in the gender-free spaces such as the corridors of train stations and inside trains and buses that I spoke with female interlocutors. I spent 18 months going in and out of the RSSTs. During this time, I also visited other toilets and train stations, and travelled on buses and trains. All participants voluntarily engaged in conversations with me. Their ages are given, but the names used are pseudonyms.

Hanging around in Public Spaces and Conducting Interviews

Unlike studies of DV which have encouraged interlocutors to talk about their experiences (Ellsberg et al. 2001), my study was not designed to delineate victims' or survivors' experiences (cf. Lamb 1999). The focus was just on eliciting perceptions and interpretations of the posters and the help cards from the general public. Yet on four occasions (see quotes below from Michael, Julia, Sandrine and Olivia), the interlocutors spontaneously related experiences and perceptions of DV more broadly (I informed my interlocutors of existing support groups and their contact number, Lifeline -131114 and Beyondblue -1300224636, in case they felt distressed). Additionally, I have considerable experience dealing with issues of violence and psychological trauma, and ethical practice and care in research, so as to be able to provide first response to any interlocutors who may be in need (Igreja 2004, 2009; Igreja et al. 2004). Although none of them showed signs of distress when telling me of their experiences, I took into account the feminist perspective that recommends that researchers 'consider victims of violence as moral agents' (Mulla and Hlavka 2011: 1512). In this regard, and in a fashion similar to how Sharon Lamb (1999: 9) considers how 'victims struggle to remain agents of their acts as they describe their victimization', I understood that my interlocutors told me of their experiences of exposure to violence not to claim victimhood and vulnerability but to demonstrate that they could speak with authority on the topic of DV.

In public toilets, I observed whether users looked at the posters mounted on the walls and whether they grabbed the help cards. I systematically asked the same questions: Did you see the posters hanging on the wall? Did you see the help cards? What is this poster about? Have you seen this poster before here or elsewhere? What is this help card about? In your opinion, why do campaign organisers use public toilets to display posters on the walls? Outside the toilets, on walkways in train stations and inside trains and buses, I used the same questions.

\section{Engaging with People in Movement}

In total, I spoke with 51 participants, all of whom were Australians of European descent. Thirty-one were men and 20 were women. Their ages ranged between 18 and 54. As the focal point of the Trust Your Instinct campaign was the RSSTs, 20 of my interviews were conducted with male toilet users in and around these sites. The other 31 participants were interviewed in stations and inside trains and buses. The sites of these interviews were the Brisbane-Ipswich train ( 2 males, 3 females), the Brisbane-Cleveland train (2 males, 3 females), Helensvale Station (2 females), Ormiston Station (4 males, 6 females), Toowoomba Station ( 2 males, 2 females), and various trains and buses (1 male, 4 females).

Data analysis was iterative. Because I visited several sites, I was able to compare the numbers of people at the different locations. I also analysed the relationship between the posters and the help card displays and people's access to these anti-violence devices. Most interviews were tape recorded and transcribed verbatim. My analysis focused on participants' responses to questions about the two posters and the help cards, and on their interpretations of the images thereon. I carried out content and thematic analysis to identify major thematic patterns and emergent themes. For instance, once I heard from an interlocutor the expression 'don't cut my grass' (see below, the case of Olivia), I started asking all my interlocutors systematically about this expression.

\section{The Roma Street Station Toilets and Visual Signs of Anti-Violence}

When I began my fieldwork in December of 2015, most users of the RSSTs on the third floor were passengers on inter-urban bus services and a few of the users were police officers who regularly drank their morning coffees in the café located on that floor. On the second floor, the majority of toilet users were clients of the nearby fast food outlets (KFC and McDonald's). On the weekends, the third floor toilets were closed and the bus passengers had to go to the second floor to use the toilets. I compared the number of people using the RSSTs in a day with the number that used other public toilets. It became clear to me that the RSSTs were used less frequently than the toi- 
lets on the ground floor of the same station and less frequently than most public toilets in the city centre.

Throughout 2016, the Trust Your Instinct campaign continued to use the RSSTs. I asked my male interlocutors in the RSSTs for their thoughts regarding the use of toilets to inform the public about DV. Their responses varied: nine thought that toilets were used in order to 'develop a discreet campaign'; six asserted that 'the use of toilets was an indication that this is not a priority issue'; three said that 'it is common in Brisbane to use toilets for conducting campaigns'; and the remaining two did not know. To better understand this apparent tension between discretion and disclosure, I followed-up by asking those that had mentioned a discreet campaign what they meant. Peter (22 years old) said: 'Perhaps the organisers don't want to disturb society', and two other interlocutors expressed similar views. The other respondent who had mentioned a 'discreet' campaign, John (43 years old), said: 'I guess the campaign organisers consider this as a problem of the lower-classes; for this reason they target places they expect to find the Aussie Battler'. Still another respondent, Andre (55 years old), told me that 'given that this is a serious problem in Australia, it's like the organisers are trying to put one finger in people's eyes and one in people's ears'. By this, Andre was implying that the campaign was conducted in ways that shielded the public from the reality of DV instead of exposing them to it directly.

Among those interlocutors who thought that the use of public toilets indicated that DV was not a priority issue, one commented that 'although public toilets in Brisbane are regularly cleaned, they are not inviting places to stay long inside and read posters. If the organisers place posters here, I guess they are not expecting people to see them, let alone read them' (Mathias, 29 years old). Another, Carl (41 years old), said: 'Toilets are places for blokes like us to discharge our bodily waste. No wonder such an embarrassing topic as DV is placed in such an embarrassing and stinking spot'. Some of my interlocutors thought that the campaign was reinforcing the silence about DV in mainstream Australia, instead of removing it from the shrouds of secrecy. Thus, place matters, given the potential to exert influence on people's behaviours (cf. Green 1999: 9). For instance, a study conducted in the toilet of a sports club at a private university in the United States to raise awareness about campus recreation programmes generated positive results, which were attributed to the strategic location and the graphics and colours of the posters (Kaltenbaugh et al. 2011). Yet its success may also be based on the fact that the toilet users were homogeneous, as they belonged to the sports club and the ads were specifically connected to activities that were to unfold on the campus. The Trust Your Instinct campaign did not have such a homogeneous intended audience, and there is no logical connection between DV and public toilets. To be effective, the anti-violence images needed to be highly visible and placed in a wider range of sites and media formats (Donovan et al. 1999; Kitzinger 1994) or, as suggested by Mathias, the help cards could be distributed on busy streets, a strategy used in other campaigns.

\section{Competing Images in Stations, Trains and Buses}

The campaign occasionally used the entrance halls of train stations and the interiors of trains and buses. These locations were strategic, given that during rush hours there was a significant presence of commuters. Yet the high density of commuters was not in itself a guarantee that they would properly notice the antiviolence ads. I observed that when the trains arrived at the platform and were still moving slowly, passengers started looking for potential seats through the windows. Once they entered the train, they focused on finding a seat to occupy. This reduced the likelihood that passengers would stop near the train doors to stare at the posters. During the entire study period, I did not see anyone stopping to look at the posters. Only those who had no seats and were standing near the doors had the chance to look at the images. Yet on many occasions when I was about to initiate a conversation, I saw that once people settled on the train they focused on their mobile phones or note pads, or they listened to music or the radio using headphones. Queensland Rail facilitated such practices by offering free $\mathrm{Wi}-\mathrm{Fi}$ access to passengers.

\section{Controlling and Obsessive Behaviour: Poster 1}

Poster 1 was widely used during the period of this study, yet 14 of the male interlocutors that I asked about it did not report noticing it in the RSSTs, while six reported seeing it. The majority of those who had not noticed it said that they had spotted something on the wall but did not grasp its content. And they had not seen the help cards at all. For instance, Peter (see above) told me that he had stood in one corner of the urinal and that, when he turned his head to the 
left, another user arrived, which led him to keep his head down until he had finished urinating. I asked him why he had given up on looking at the wall. He answered: 'If I had turned my head, it could give the impression that I wanted to spot the other user's private parts'.

Another user, John (see above), also said that he had felt compelled to respect the privacy of the other user, as he also expected others to respect his privacy. I asked him whether it was possible to have privacy in a public toilet. He answered: 'I guess what I am trying to say is that, as users, good etiquette does not expect us to look, or to be seen as if keenly looking, at other users' private parts'. Following Moore's work on colonial manhood and masculinities, this visual avoidance of other males' private parts could be suggestive of masculinities and the 'modern mateship' (1998: 46) which appears intolerant to 'expressions of sexuality beyond the male-female norm' (44). This pattern has not changed significantly in the post-colony, given that 'in contemporary Australian society the most emotionally powerful line of demarcation though by no means the only one - is between heterosexual and homosexual masculinities' (Connell 2003: 14). As I continued my conversation with John, he further added that 'if something is made for me to see it, it has to be accessible'. These explanations suggested that, even in such a small toilet as the RSSTs, users sometimes did not see Poster 1 given the visual expectations in public toilets, expectations that are charged with masculine norms.

The other six interlocutors said that Poster 1 was eye-catching, yet three of them thought that it was about depression or suicide; two others thought that it was about women's periods, and one just said that he did not agree with the poster's content. I asked him (Michael, 45 years old) why he disagreed with it, and he told me that 'there is an exaggeration in Australia about domestic violence'. Michael was the first interlocutor to unexpectedly expand on his views beyond my question about the posters. He said: 'Very often the news is about male violence against a woman. Yet often there is violence on both sides, and I personally went through such experiences. The difference is that men use physical violence whereas women use psychological violence'. To conclude, he said: 'I never see or hear about men's exposure to psychological violence perpetrated by women, and this poster is another confirmation of this'.

I asked those who mentioned depression or suicide why they reached this conclusion. Two of them said that the woman in the poster 'looks sad, so I reckoned it's about depression or anxiety'. One in- terlocutor also added that 'prior to this poster there was another one on depression, although using a male's face'. Another interlocutor said that 'at least the word "violence" in this poster [Poster 1] should be enlarged so that it becomes more visible". Given the identification of Poster 1 with depression, I asked my interlocutors about what they thought images portraying violence would look like. Some mentioned 'confronting images such as bleeding faces or body parts'. Others referred to 'violent instruments'. I also asked them about what images could depict 'controlling behaviour'. Most of their responses, such as 'a man squeezing a woman's neck'; 'a person's mouth closed with insulating tape indicates incapacity to have a voice because someone is running the show, and a woman wearing trousers and tie is the same thing to me'; and 'a man wearing a female dress is an indication of controlling behaviour', also focused on dramatic representations. These popular representations of controlling behaviour are consistent with the idea that in the contemporary world of media imagery domination 'ideal criminals and ideal victims can be recognized by physical characteristics' (Madriz 1997: 352), and that these characteristics were absent in Poster 1 and on the help card.

The fact that the majority of men $(70 \%)$ reported not seeing Poster 1 and that there was confusion demonstrated by the interlocutors $(30 \%)$ who did see it can partly be explained by the RSSTs' having been used for campaigns related to other health issues. As some interlocutors mentioned, an earlier poster on depression had captured their attention in such a way that the meaning of the image thereon had become seemingly self-evident (Belting 2011).

\section{Controlling and Obsessive Behaviour: Poster 2}

Poster 2 was eye-catching. Eighty per cent of my interlocutors at Ormiston Station reported seeing it, although it was on display for a shorter period of time than Poster 1, which was in the RSSTs. Most interlocutors said that the poster caught their eye because they were fascinated by the woman's divided face. One female respondent, Mary (26 years old), said: 'The bruise on her eye is too compelling to avoid. When I first saw it, I asked myself, "what happened to her?" That's when I read the poster to get more information about it'.

It is noteworthy, however, that besides Mary and one other interlocutor a significant proportion of interlocutors who had seen Poster 2 could not tell right 
away that the ad was about DV prevention. Three interlocutors recognised in general terms that it must be a serious issue'; two said 'it is about binge drinking'; and one said it was about 'a forthcoming film'. Other commuters spotted the image and just one part of the text, which reads: 'Don't let concern become regret'. This part triggered different interpretations. Three interlocutors thought that it was about 'unresolved grief"; two thought of marital issues such as 'divorce'; another two thought it referred to 'problems with children or neighbours', and still another said that it had to do with 'financial issues'.

The response to Poster 2 suggested that my interlocutors focused on visual cues that were familiar to them, particularly when looking at images evoking dramatic events. The bruised eye and a face divided in half imaginatively suggested violence, disruption and fragments of a person. In this regard, the fragmentation could have worked as a visual metaphor (Messaris 1997: 10), and this type of 'violation of reality attracts attention' (13). Yet the majority of my interlocutors did not understand right away the intended meaning of Poster 2. What the Trust Your Instinct campaign gained by using strategic locations was sapped by the fact that images do not speak for themselves (cf. Belting 2011) and the fact that the city sites were filled with competing images.

\section{Talking beyond Images of Anti-Violence}

My queries about people's perceptions of the Trust Your Instinct posters and help cards also created a context which some interlocutors used to reveal their own personal experiences and understandings of DV. For instance, Julia (29 years old) told me that 'there is a lot of misconception about DV in Australia'. On her own initiative, she said: 'I was beaten two times and insulted many times, but it was not my partner. It was my younger brother'. She further told me that her younger brother 'insulted me many times, saying that I am useless, I am older but I was still unmarried and without children. Two weeks ago, I responded to his insults and he beat me'.

I asked Julia about reporting her experiences to the police. She answered negatively, adding: 'Mom told me to hush-hush and keep it in the family'. I further asked Julia whether it was not worth informing the police to stop the violence. She answered: 'If it was someone outside my family, surely my mother and I could have reported it immediately to the police'. I then asked Julia why she mentioned the existence of a 'misconception' in relation to DV in Australia. She answered: 'Mom actually blamed me. She said that when my brother insults me I should just let it go because it's the boy's ways'. In relaying this experience, Julia wanted to contradict the popular view that regards men as perpetrators and women as victims by highlighting the complicity of her mother. As Julia told me, her mother often sided with her brother in legitimating DV while she regularly advised Julia to keep the violent conflicts inside the family in order to, as she also said, 'to avoid shaming our family'.

Another interlocutor, Sandrine (23 years old), also unexpectedly said: 'My mother used to provoke my father, saying, "I am hiring a plumbi [plumber]"'. While this was a joke to suggest that her mother had control of her sexuality because she flirted with plumbers when her husband was absent, Sandrine said that her father often felt humiliated. She recalled how her father 'used to say that a man controls his castle, and used to beat my mother'. Sandrine's experiences revealed that DV in her family was triggered by serious disagreements between her parents. She asserted that, while her father 'had no right' to beat her mother, her mother 'was no less responsible for escalating their disagreements into hostile confrontations'.

Still another respondent, Olivia (35 years old), said: 'I broke relationships three times with my previous partners because of jealousy'. I asked Olivia how jealousy had manifested in her relationships. She answered by asking me a question: 'Do you know the expression "don't cut my grass"?' She explained that 'men that I have known in Brisbane did not stand seeing their girlfriends talking to other men that they did not know, let alone go out with them'. I asked Olivia whether she had just been unfortunate in finding male partners that were jealous. She answered: 'Several friends of mine went through similar experiences; many times their boyfriends treated them as grass which no other men should dare to cut'. She also volunteered that, while she had not been physically assaulted, one of her boyfriends 'used to make threats of violence because of jealousy'. I asked several male and female interlocutors about the expression 'don't cut my grass'. A number of them knew about it, although they linked it to working class men who used the expression to convey their sense of ownership over the female body and to preserve their sense of honour. While ownership of the female body can only be apparent and always incomplete, such sentiments of honour 'reproduce social understandings of masculinity' (Tomsen 2003: 
95) and reflect ideas of selective monogamous sexuality, in that social conventions expect women to be sexually loyal to their male partners while men can be free riders, albeit with discretion.

\section{Making Sense of Veiled and Unveiled Observations and Conversations}

Contemporary analysis of DV in Australia cannot be separated from the historical analysis of the establishment of social and institutional relations, while ideas about Australian masculinities 'do not make much sense until' they are 'seen as part of the history of settler colonialism, dependent industrialization, and contemporary globalization' (Connell 2003: 19). Until recently, in the dominant regimes of representation (Hall 1990: 225), minority groups, particularly Aboriginals, have been publicly denounced as violent, and subjected to state surveillance and disciplinary practices. In the Australian colonial context, mainstream Australians were defined as harmless; scenes of violence were interpreted as individual lapses of reason, and most of the time they were silenced and hidden. Recently, political elites, civil society individuals and groups, and campaign organisers have publicly focused on DV in mainstream communities. Yet the legacies of the dominant regimes of representation have endured, which continuously hinders efforts to openly deal with DV in mainstream communities. For example, the ways in which Julia and her family dealt with DV have also been alluded to in the media through revelations of wives of members of the Australian Defence Force that have suffered with DV in silence (Rabb 2012). Oher survivors of sexual violence in Australia have indicated that a culture of fear and shame inhibits women from speaking out (Day and Fernandez 2015; Despoja 2015; Moss 2014; Trenoweth 2015). Such a culture of silence, fear and shame is also ambivalent, given that the identity of the perpetrator also shapes decisions about whether victims ultimately report to the police or not. Julia's story suggests that silence was not directly influenced by fear: had an outsider been the perpetrator, Julia and her mother could have informed the police. Similarly, when I asked Sandrine, Olivia and Michael whether they had sought police intervention, all three said, in different ways, that this would have been considered unacceptable in their families and among their friends.

Thus silence in mainstream communities cannot be interpreted solely as being symptomatic of psy- chological troubles, powerlessness and fear of perpetrators. Silence needs to be interpreted as a form of social action that contributes to the preservation of the status quo, even though it has officially been challenged and all victims in mainstream circles are expected to report incidents of DV to the authorities. This is not happening, however, and consequently when silence is publicly broken DV becomes the subject of headline fury and DV is denounced as 'unAustralian', as if it has encroached on mainstream circles from the outside. If we agree with Herzfeld (2005: 78) that 'nationalism deprives the essentially moral terminology of identity of its relativity', being 'unAustralian' is part of what it means to be Australian ranging from the political appeal to egalitarianism and fair go, to the ongoing everyday life and foundational experiences replete with a myriad of violent episodes (cf. Dixson 1976; Encel et al. 1975; Evans 1992; Kahn 1980; Moore 1998; and Tomsen 2003). The tracks of this legacy were also suggested by DVConnect's systematic display of anti-violence images in unfrequented public toilets and by the binary approach which invariably sticks to the customary division of men as perpetrators and women as victims. Although this split is also sustained by local and global statistics, statistics only reveal outcomes and not processes. The views expressed by some of my interlocutors alluded to processes involving competing responsibilities, contested legitimacy and multiple subject positions (cf. Das et al. 1997; Riches 1986). Michael alluded to experiences of psychological violence inflicted upon him by his former female partner, and Julia suggested that her mother was complicit in male violence.

Sandrine's testimony shows how DV was the result of a breakdown of relationships, the feelings of humiliation felt by her father, and the inability of both sides to peacefully engage in conflict resolution. Nevertheless, none of these interlocutors framed the violence as an accepted action (cf. Jakobsen 2014). Furthermore, Olivia revealed experiences of honour violence, which are often attributed to people in non-Western worlds, or people that have migrated to Western nations (Cooney 2014). Interviews with other interlocutors revealed that 'don't cut my grass' was a well-known notion locally. This notion is also reminiscent of historical descriptions whereby women were regarded as custodians of morality in the sexual sphere (Saunders 1984: 83; Saunders and Taylor 2009: 178).

In her book on personal experiences of DV, Rosie Batty (2015) provides various accounts that reveal the complex issue of competing responsibilities and 
subject positions that further challenge the binary analysis of DV. Batty presents various examples of the ordinariness of violence which also show how victimhood was sometimes co-constructed through multiple informal and formal relationships. Overall, this study suggests that explanations for DV and the creation of persuasive languages of prevention should include considerations of historical changes and continuities in perceptions and meanings (Gibson-Graham 1995; Saunders 1984), intersubjective responses to violence (Cerulo 1998) and a deeper analysis of the implications of visual campaigns in cosmopolitan spaces which are filled in with images that aggressively compete for viewers' attention. Campaigns could integrate local people's notions and diverse expressions of anti-violence. The ambivalence surrounding talking about and denouncing perpetrators suggests a need to expand anti-violence messages from a narrow focus on asking people to call and denounce perpetrators, to creating spaces for open conversations about DV. There is also a need for more ethnographic research focused on the dynamics of DV in everyday life. Finally, future studies should analyse service providers and the dynamics of decision-making regarding the styles of visual campaigns, and the sites used for such campaigns.

Victor Igreja is a senior lecturer at the University of Southern Queensland, Toowoomba, Australia. He teaches international relations, anthropology and conflict and peace studies. He is a member of the research group Felix Culpa: Toward a Theory of Productive Guilt (Center for Interdisciplinary Research, Bielefeld University), and Research Fellow at the School of Social Science, University of Queensland. E-mail: victor.igreja@usq.edu.au

\section{Notes}

1. DVConnect also provides free phone counselling, emergency transport, shelter, community education and referral to women's refuges.

2. Source: http://www.dranthonylynham.com.au/tru st-your-instinct-during-domestic-and-family-vio lence-prevention-month/.

3. Source: http://www.brisbanetimes.com.au/queens land/trust-your-instinct-campaign-to-combat-do mestic-violence-20150501-1mxrv2.html.

4. www.dranthonylynham.com.au/trust-your-instinctduring-domestic-and-family-violence-preventi on-month/.

5. See note 4 .

\section{References}

Altman, J. and M. Hinkson (2010), Culture Crisis: Anthropology and Politics in Aboriginal Australia (Sydney: University of New South Wales Press).

Anderson, S. (2016), 'Julia Gillard Says Women Going into Politics should Expect Rape Threats', $A B C, 12$ October. http://www.abc.net.au/news/2016-10-12/ expect-rape-threats,-gillard-warns-female-politicia ns/7925906.

Barker, B., L. Lamb and G. Campbell (2016), 'The Mine Island Aboriginal Stone Arrangements: Spiritual Responses to Late Holocene Change on the Central Queensland Coast', Australian Archaeology 82, no. 3: 232-247.

Batty, R. (2015), A Mother's Story (Sydney: Harper Collins Publishers).

Baxter, J. and E. Kane (1995), ‘Dependence and Independence: A Cross-National Analysis of Gender Inequality and Gender Attitudes', Gender \& Society 9, no. 2: 193-215.

Belting, H. (2011), An Anthropology of Images: Picture, Medium, Body (Princeton: Princeton University Press).

Biber, K. (2006), 'The Specter of Crime: Photography, Law and Ethics', Social Semiotics 16, no. 1: 133-149.

Borzekowski, D. and A. Poussaint (1999), 'Public Service Announcement Perceptions: A Quantitative Examination of Anti-Violence Messages', American Journal of Preventive Medicine 17, no. 3: 181-188.

Caine, B. and R. Pringle (1995), Transitions: New Australian Feminisms (Sydney: Allen \& Unwin).

Carrington, K. and A. Pratt (2003), 'How Far Have We Come? Gender Disparities in the Australian Higher Education System', Australian Government Current Issues Brief No. 31.

Cerulo, K. (1998), Deciphering Violence: The Cognitive Structure of Right and Wrong (New York: Routledge).

Cooney, M. (2014), 'Death by Family: Honor Violence as Punishment', Punishment \& Society 16, no. 4: 406-427.

Connell, R. W. (2003), 'Australian Masculinities', in S. Tomsen and M. Donaldson (eds.), Male Trouble: Looking at Australian Masculinities (Victoria, Australia: Pluto Press), 9-21.

Das, V., A. Kleinman, M. Ramphele and P. Reynolds (eds.) (1997), Violence and Subjectivity (Berkeley: University of California Press).

Day, A. and E. Fernandez (eds.) (2015), Preventing Violence in Australia (Sydney: The Federation Press).

Despoja, N. (2015), 'A National Emergency', in S. Trenoweth (ed.), Fury: Women Write about Sex, Power and Violence (Melbourne: Hardie Grant Books), 83-92. 
Dixson, M. (1976), The Real Matilda: Woman and Identity in Australia, 1788-1975 (Sydney: Penguin Books).

Donovan, R., D. Paterson and M. Francas (1999), 'Targeting Male Perpetrators of Intimate Partner Violence', Social Marketing Quarterly 5, no. 3: 127-144.

Ellsberg, M., L. Heise, R. Pena, S. Agurto and A. Winkvist (2001), 'Researching Domestic Violence against Women: Methodological and Ethical Considerations', Studies in Family Planning 32, no. 1: $1-16$.

Encel, S., N. MacKenzie and M. Tebbutt (1975), Women and Society: An Australian Study (London: Malaby Press).

Evans, R. (1992), 'A Gun in the Oven: Masculinism and Gendered Violence', in K. Saunders and R. Evans (eds.), Gender Relations in Australia: Domination and Negotiation (Sydney: Harcourt Brace Jovanovich), 197-214.

Gadd, D., M-L. Corr, C. Fox and I. Butler (2014), 'This Is Abuse... Or Is It? Domestic Abuse Perpetrators' Responses to Anti-Domestic Violence Publicity', Crime Media Culture 10, no. 1: 3-22.

Gebert, J. (2016), 'Our Action on DV Is like Throwing Popcorn at the Taliban', The Guardian, 27 May. https://www.theguardian.com/commentisfree/2016/ may/27/our-action-on-domestic-violence-is-likethrowing-popcorn-at-the-taliban.

Gershenson, O. and B. Penner (2009), 'Introduction: The Private Life of Public Conveniences', in O. Gershenson and B. Penner (eds.), Ladies and Gents: Public Toilets and Gender (Philadelphia: Temple University Press), 1-32.

Gibson-Graham, J. K. (1995), 'Beyond Patriarchy and Capitalism', in B. Caine and R. Pringle (eds.), Transitions: New Australian Feminisms (Sydney: Allen \& Unwin), 172-183.

Goldman, R. and S. Papson (1996), Sign Wars: The Cluttered Landscape of Advertising (New York: The Guilford Press).

Green, L. (1999), Fear as a Way of Life (New York: Columbia University Press).

Hage, G. (1998), White Nation: Fantasies of White Supremacy in a Multicultural Society (Victoria, Australia: Pluto Press).

Hall, S. (1990), 'Cultural Identity and Diaspora', in J. Rutherford (ed.), Identity: Community, Culture, Difference (London: Lawrence \& Wishart), 222-237.

Herzfeld, M. (2005), Cultural Intimacy: Social Poetics in the Nation-State (New York: Routledge).

Hernández, T. (1941), 'Children among the Drysdale River Tribes', Oceania 12, no. 2: 122-133.

Hill, A. (2000), 'A Social Drama: Anti-Violence Campaign Groups and Media Violence', in D. Berry (ed.), Ethics and Media Culture (Oxford: Focal Press), 248-261.

Igreja, V. (2004), 'Mental Health in a Postwar Society', in P. Morrall and M. Hazelton (eds.), Mental Health Global Policies and Human Rights (London: Whurr Publishers), 166-182.

Igreja, V. (2009), 'The Politics of Peace, Justice and Healing in Post-war Mozambique', In C. Sriram and S. Pillay (eds.), Peace versus Justice? The Dilemma of Transitional Justice in Africa (KwaZulu-Natal, South Africa: University of Kwa-Zulu Natal Press), 277-300.

Igreja, V. (2015), 'Media and Legacies of War: Responses to Global Film Violence in Conflict Zones', Current Anthropology 56, no. 5: 678-700.

Igreja, V., W. Kleijn, B. Schreuder, J. van Dijk and M. Verschuur (2004), 'Testimony Method to Ameliorate Post-Traumatic Stress Symptoms: Community-Based Intervention Study with Mozambican Civil War Survivors', British Journal of Psychiatry 184: 251-257.

Ireland, J. (2015), 'Malcolm Turnbull's Scathing Attack on Men Who Commit Domestic Violence', The Sydney Morning Herald, 24 September. http://www .smh.com.au/federal-politics/political-news/mal colm-turnbulls-scathing-attack-on-men-who-com mit-domestic-violence-20150923-gjtpqt.html.

Jakobsen, H. (2014), 'What's Gendered about GenderBased Violence?', Gender \& Society 28, no. 4: 537-561.

Kahn, M. (1980), 'Wife Beating and Cultural Context: Prevalence in an Aboriginal and Islander Community in Northern Australia', American Journal of Community Psychology 8, no. 6: 727-731.

Kaltenbaugh, L., J. Molnar, W. Bonadio and B. Dorsey (2011), 'A Study on Restroom Advertising and its Effects on Awareness of Campus Recreation Programs', Recreational Sports Journal 35, no. 1: 3-11.

Kitzinger, J. (1994), 'Challenging Sexual Violence against Girls', Child Abuse Review 3, no. 4: 246-258.

Kilbourne, J. (1999), Deadly Persuasion: Why Women and Girls Must Fight the Addictive Power of Advertising (New York: The Free Press).

Krug, E. G., Linda L. Dahlberg, James A. Mercy, Anthony B. Zwi and R. Lozano (eds.) (2002), World Report on Violence and Health (Geneva: World Health Organization).

Lamb, S. (ed.) (1999), New Versions of Victims: Feminists Struggle with the Concept (New York: New York University Press).

Madriz, E. (1997), 'Images of Criminals and Victims', Gender and Society 11, no. 3: 342-356.

Malefyt, T. and R. Morais (2012), Advertising and Anthropology: Ethnographic Practice and Cultural Perspectives (London: Berg). 
McDonald, P. and R. Stuart (2017), 'Royal Commission into Child Sexual Abuse: 1,880 Alleged Perpetrators Identified in Catholic Church', $A B C, 7$ February. http://www.abc.net.au/news/2017-02-06/royal-com mission-into-child-sexual-abuse-begins-in-sydney/ 8242600.

Meggitt, M. (1964), 'Indigenous Forms of Government among the Australian Aborigines', Bijdragen tot de Taal-, Land-en Volkenkunde 1: 163-180.

Merlan, F. (2006), 'European Settlement and the Making and Unmaking of Aboriginal Identities', The Australian Journal of Anthropology 17, no. 2: 179-195.

Messaris, P. (1997), Visual Persuasion: The Role of Images in Advertising (London: SAGE).

Meyer, S. (2011), 'Seeking Help for Intimate Partner Violence', Feminist Criminology 6, no. 4: 268-290.

Moore, C. (1998), 'Colonial Manhood and Masculinities', Journal of Australian Studies 22, no. 56: 35-50.

Moore, D. and R. Singh (2017), 'Seeing Crime, Feeling Crime: Visual Evidence, Emotions, and the Prosecution of Domestic Violence', Theoretical Criminology 22, no. 1: 1-17.

Moss, T. (2014), The Fictional Woman (Sydney: Harper Collins Publishers).

Mulla, S. and H. Hlavka (2011), 'Gendered Violence and the Ethics of Social Science Research', Violence against Women 17, no. 12: 1509-1520.

Rabb, K. (2012), 'A Silent Epidemic: Spousal Abuse Is the Military's Best Kept Secret', Huffington Post, 26 March. https://www.huffingtonpost.com/kim-rabb/ best-kept-military-secret_b_1373462.html.

Reynolds, H. (1972), 'Violence, the Aboriginals, and the Australian Historian', Meanjin Quarterly 31, no. 4: 471-477.

Riches, D. (1986), The Anthropology of Violence (Oxford: Blackwell).

Saunders, K. (1984), 'The Study of Domestic Violence in Colonial Queensland', Historical Studies 21, no. 82: 68-84.

Saunders, K. (1997), 'Feminist Issues in Queensland in the $1890 s^{\prime}$, in B. Shaw (ed.), Brisbane: Corridors of
Power (Kelvin Grove, Australia: Brisbane History Group), 125-131.

Saunders, K. and H. Taylor (2009), "“To Combat the Plague": The Construction of Moral Alarm and State Intervention in Queensland during World War II', in C. Ferrier and D. Jordan (eds.), Hibiscus and TiTree: Women in Queensland (St Lucia: Hecate Press), 173-196.

Schapper, J. (2012), 'The Writing Is on the Wall: The Text(ure) of Women's Toilets in Australia', Gender, Place $\mathcal{E}$ Culture 19, no. 4: 494-517.

Spearritt, K. (2009), 'The Market of Marriage in Colonial Queensland', in C. Ferrier and D. Jordan (eds.), Hibiscus and Ti-Tree: Women in Queensland (St Lucia: Hecate Press), 46-62.

Stewart, P. and A. Strathern (2002), Violence: Theory and Ethnography (London: Continuum).

Stilwell, F. and K. Jordan (2007), Who Gets What? Analysing Economic Inequality in Australia (Cambridge: Cambridge University Press).

Taylor, R. (2014), 'My Story: I Was a Victim of Domestic Violence', The Australian Women's Weekly, 25 February.

Tomsen, S. (2003), “A Gross Overreaction”: Violence, Honour and the Sanctified Heterosexual Male Body', in S. Tomsen and M. Donaldson (eds.), Male Trouble: Looking at Australian Masculinities (Victoria, Australia: Pluto Press), 91-107.

Trenoweth, S. (ed.) (2015), Fury: Women Write about Sex, Power and Violence (Melbourne: Hardie Grant Books).

Trigger, D., and R. Martin (2016), 'Place, Indigeneity, and Identity in Australia's Gulf Country', American Anthropologist 118, no. 4: 824-837.

Uhlmann, A. (2006), Family, Gender and Kinship in Australia (Burlington, VT: Ashgate).

Wakefield, M., B. Loken and R. Hornik (2010), 'Use of Mass Media Campaigns to Change Health Behaviour', The Lancet 376, no. 9748: 1261-1271.

Whitehead, N. and S. Finnström (eds.) (2013), Virtual War and Magical Death: Technologies and Imaginaries for Terror and Killing (Durham, NC: Duke University Press). 